\title{
Effects of growth conditions and cultivability on the content of cyclitols in Medicago sativa
}

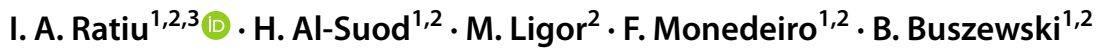

Received: 31 January 2020 / Revised: 27 May 2020 / Accepted: 16 June 2020 / Published online: 12 September 2020

(c) The Author(s) 2020

\begin{abstract}
Cyclitols are secondary metabolites with bioactive properties, naturally occurring in plants. Accumulation of such metabolites is directly connected with abiotic stressing factors. This article investigates the influence exercised by a series of abiotic factors including plant treatment with elicitors and cultivability in various regions of Europe, in some cases during two seasons, onto the amounts of cyclitols produced in alfalfa (Medicago sativa L.). The obtained results highlighted that $\mathrm{NaCl}$ elicitation acts to increase the quantity of cyclitols, while $\mathrm{AgNO}_{3}$ and $\mathrm{Zn}\left(\mathrm{NO}_{3}\right)_{2}$ generally decreased the obtained amount of cyclitols. When considering the seasonal impact, samples harvested in August presented a double amount of cyclitols in comparison with those collected in May. Correlation analysis proved that this phenomenon is related mainly to sunshine period versus low humidity. However, our investigation suggests that soil type, salinity level, lack of humidity, the number of sunny days, and plant elicitation play a role on the amount of cyclitols produced in alfalfa plant.
\end{abstract}

Keywords Cyclitols $\cdot$ Elicitors' impact $\cdot$ Abiotic factors influence $\cdot$ Alfalfa

\begin{tabular}{|c|c|}
\hline \multicolumn{2}{|c|}{ Abbreviations } \\
\hline PAL & Henylalanine ammonialyase \\
\hline DMSO & Dimethyl sulfoxide \\
\hline TMSI & Trimethylsilylimidazole \\
\hline $\mathrm{Cfb}$ & Temperate oceanic climate \\
\hline Dfb & Warm-summer humid continental climate \\
\hline $\mathrm{Cfa}$ & Humid subtropical climate \\
\hline an.av.h.t. & Annual average high temperature \\
\hline an.av.l.t. & Annual average low temperature \\
\hline an.av.t. & Annual average temperature \\
\hline av.an.ppt. & Average annual precipitation \\
\hline ppt. $\left(\mathrm{d} \mathrm{yr}^{-1}\right)$ & Days per year with precipitation \\
\hline m.an.h.s. & Mean annual hours of sunshine \\
\hline
\end{tabular}

Editorial responsibility: Josef Trögl.

B. Buszewski

bbusz@chem.umk.pl

1 Interdisciplinary Centre of Modern Technologies, Nicolaus Copernicus University, Wileńska 4, 87-100 Toruń, Poland

2 Department of Environmental Chemistry and Bioanalytics, Faculty of Chemistry, Nicolaus Copernicus University, Gagarina 7, 87-100 Toruń, Poland

3 "Raluca Ripan" Institute for Research in Chemistry, Babes-Bolyai University, 30 Fantanele, RO-400239 Cluj Napoca, Romania

\section{Introduction}

Since plants cannot get away from extreme abiotic factors such as light, drought, low or high temperatures, nor to move to more favorable regions, they are forced to develop mechanisms through which to protect themselves in order to adapt to the conditions they are exposed. The environmental factors like: temperature, light intensity and duration over a day, atmospheric humidity, the amount of precipitation, minerals provided by various soil types may all strongly influence the growth of a plant and hence secondary metabolites production (Ncube et al. 2012).

The secondary metabolites, called phytochemicals are bioactive compounds, naturally synthesized in all plants. Some examples of secondary metabolites are: cyclitols, polyphenols, flavonoids alkaloids, tannins, terpenoids, coumarins, etc. The minor phytochemicals, including cyclitols, are not directly involved in the normal development and growth of plants; however, they play an important role in plant interactions with its surrounding environment, for adaptation and self-defense. By their chemical structure cyclitols, are hydroxylated cycloalkanes (cyclic polyols), derived from glucose. It was described that often cyclitols may confer protection against environmental stresses such as salinity or water deficit (Hossain et al. 2017), or they may act as cryoprotectants (Orthen and Popp 2000). Among the 
cyclitols, myo-inositol was specifically found to be stockpiled in halophytes, acting as an osmolyte (Sengupta and Majumder 2010), while its derivatives have the ability to regulate salt stress response by serving as compatible solutes and signaling molecules (Kido et al. 2013).

Biological activity of the cyclitols (as either anti-diabetic, anti-inflammatory, or even anticancer agents) was investigated by some researchers (Hernandez-Mijares et al. 2013; Rengarajan et al. 2015) and reviewed in several articles (AlSuod et al. 2017; Ligor et al. 2018; Al-Suod et al. 2019a, b). Myo-inositol efficiency in disorders like panic attacks, premenstrual dysphoric, depression, or obsessive-compulsive behavior was demonstrated and described in a review article (Al-Suod et al. 2017). D-pinitol has been successfully used for treating hypertension, rheumatoid arthritis, cardiovascular or neurological disorders (Zheng et al. 2017). Both D-chiro-inositol and myo-inositol proved efficacy in improving functionality of the ovaries, by increasing the ovulation rate in those women suffering from polycystic ovary syndrome (Cheang et al. 2008; Costantino et al. 2009). Production of these compounds, often in less than $1 \mathrm{mg} / \mathrm{g}$ of dried plant (Al-Suod et al. 2018a; Ratiu et al. 2018), largely depends on plant developmental stage, on the morphological parts investigated, or even the very product analyzed (Al-Suod. 2018b, Ratiu et al. 2019, 2020). However, the crucial role in cyclitols production is played by environmental stresses and plants elicitation. Growing conditions have therefore a direct impact on those metabolic pathways that are being responsible for cyclitols accumulation as well.

\section{Plant elicitors as key induction factors in cyclitols formation}

Elicitors are physical or chemical factors that can induce a plant response as a result of their interaction. In our case, elicitation is the process of enhancing the synthesis of secondary metabolites by alfalfa plants that can help them to ensure their survival persistence.

When plants are subject to abiotic stresses, secondary metabolite synthesis can be increased as an after effect of the growing process being inhibited, and thus the surplus of carbon produced during photosynthesis is being predominantly allocated to secondary metabolites instead of primary metabolites (Bennett and Wallsgrove 1994; Sengupta et al. 2008; Sengupta and Majumder 2010; Kido et al. 2013; Loewus and Murthy 2000).

Salt stress produces both ionic toxicity and osmotic related stress in plants (Ramakrishna and Ravishankar 2011), leading to an increase in secondary metabolites in the halophytes. For example, it was documented that in alfalfa roots, proline content has doubled when salt stress was applied (Petrusa and Winicov 1997). Identification and quantification of carbohydrates in roots, bacteroids, and cytosol within the alfalfa nodules was also investigated. The obtained results highlighted that D-pinitol concentration was slightly modified in roots and strongly increased in cytosol and bacteroids under salt stress, while ononitol increased more or less in all three investigated fractions (Fougere et al. 1991). In case of Lupinus luteus L. an increasing trend of cyclitols (D-pinitol, D-chiro-inositol and myo-inositol) was achieved when the salinity level was supplemented with different $\mathrm{NaCl}$ concentrations (between 0 and $400 \mathrm{mM}$ ). The same researchers group tested the capacity of Lemna minor $L$ to accumulate cyclitols under salinity stress. Concentrations (between 0 and $400 \mathrm{mM}$ ) of $\mathrm{NaCl}$ were used for plants watering and subsequently increased quantities of D-pinitol and D-chiro-inositol were obtained (Sikorski et al. 2013). Changes in metabolites and secondary metabolites associated with salinity tolerance in sugar beet were investigated as well, at both cellular and subcellular level. In case of polyols (like glycolate, inositol and mannitol), the study highlighted the increasing of quantities from 3 to $339 \mathrm{~h}$ of exposure to salt stress (Hossain et al. 2017).

Silver nitrate $\mathrm{AgNO}_{3}$ elicited in the Brugmansia candida cultures the surplus production of two alkaloids, scopolamine and hyoscyamine, specifically in hairy root (PittaAlvarez et al. 2000). However, to the best of our knowledge no effect of $\mathrm{NaCl}, \mathrm{Zn}\left(\mathrm{NO}_{3}\right)_{2}$ or $\mathrm{AgNO}_{3}$ elicitation on alfalfa was investigated so far.

\section{Climatic factors-a force behind secondary metabolites generation}

The local geo-climate and environmental conditions like temperature, light, quantities of precipitation, or seasonal changes, may affect composition and quantities of secondary metabolites produced in plants (Morison and Lawlor 1999). For example, the synthesis of saponins as a response to abiotic stresses lead to tolerance and adaptability of Panax (Szakiel et al. 2011).

The light is definitely one of the physical factors that may strongly affect both production and composition of these secondary metabolites. A net positive correlation was found between increasing light intensity and the levels of phenolic compounds synthesis (Kulbat 2016). Moreover, the UV-B radiation has increased the activity of both flavonoids content and phenylalanine ammonialyase (PAL), which was directly connected with a diminution of chlorophyll content (Liang et al. 2006). Another group of researchers proved that under six different daily doses of UV-A and UV-B radiation tannins were accumulated, whereas the amount of their precursor $(+)$-catechin decreased dramatically (Lavola et al. 2003). Ginseng plants exposed for a longer period to sunlight were found to contain a higher root ginsenoside contents when compared to those directly exposed for shorter periods (Li et al. 1996). 
Another abiotic factor that strongly influences plants metabolic activity is the temperature. Temperature variations can alter the metabolism and hence affect the growth and influence the secondary metabolites production. High temperatures can trigger the premature senescence of the leaves (Morison and Lawlor 1999). Low soil temperatures caused increasing amounts of saponins in Panax ginseng (Szakiel et al. 2011). Medicago sativa $\mathrm{L}$. accumulated putrescine under low temperature stress (Nadeau et al. 1987). Moreover, it was demonstrated that lower temperatures facilitate anthocyanin accumulation, but reduces cell growth. For example, in case of strawberry, the maximum amount of anthocyanins was obtained at $15{ }^{\circ} \mathrm{C}$ and this content has been 13-fold higher than that produced at $35^{\circ} \mathrm{C}$ (Zhang et al. 1997).

Excess or deficiency of water can dramatically affect plant development and secondary metabolites production. Drought stress accompanied by solar radiation and high temperatures can affect plant development by causing oxidative stress. In the case of willow leaves, drought stress was revealed to increasing the quantities of phenolic acids and flavonoids (Larson 1988). However, one of flavonoids' roles is to deliver a protective function in case of water deficit, or in case of growing plants in the soils rich in toxic metals (Winkel-Shirley 2001). Soil type can also induce a nutrient stress in plants. For example, a three times increasing of anthocyanidins quantity and a double amount of quercetin-3-O-glucoside in tomato were observed under nutrient stress (Bongue-Bartelsman and Phillips 1995). Moreover, it was found that nitrogen and phosphate deficiency lead in accumulation of phenyl propanoids (Dixon and Paiva 1995). Sucrose, which induces osmotic stress, has the potential to control synthesis of anthocyanin in Vitis vinifera (Tuteja and Mahajan 2007).

Based on this evidence of abiotic factors' role in the genetic mechanisms of secondary metabolites regulation in plants, one may ask the following question: Can the plant's environment be manipulated in that specific manner to turn over their metabolism and to further increase, this way, production of the secondary metabolite of interest? The answer may possibly be affirmative, but is this a simple process, taking in account the multiplicity of factors necessary for plant's development? The focus of the present article is exactly the influence of abiotic factors onto production of cyclitols in alfalfa (Medicago sativa L.). Because cyclitols are important secondary metabolites that help the plants in overcoming stress conditions, some elicitors-which play the specific role of stressing agents-were used. Moreover, plants cultivated in different countries, with different types of soil and various climates, were investigated. Finally, because plants have their own life cycle that is unfolding and changing from spring to autumn, plants harvested in two different seasons were investigated as well. To the very best of our knowledge, neither the effect of seasonal impact, nor spatial distribution on cyclitols' occurrence in alfalfa plant was investigated before. The bioactive properties of cyclitols, as secondary metabolites of alfalfa, make this plant an important resource when speaking about discovery of novel drugs. The strength of our study consists therefore in finding and bringing together relevant abiotic factors which proved to stimulate the production of cyclitols in alfalfa, and may lead into a significant increasing of cyclitols amount in other plants as well. This study was carried out in Poland in October-December 2018.

\section{Materials and methods}

\section{Chemicals involved and plant material collection}

Chemicals: D-pinitol, myo-inositol, scyllo-inositol, D-chiroinositol, with purity $\geq 95 \%$, trimethylsilylimidazole TMSI (used for derivatization), Dowex ${ }^{\circledR} 1 \mathrm{X} 8$ chloride form (100-200 mesh) resin, the elicitors $\left(\mathrm{AgNO}_{3}, \mathrm{Zn}\left(\mathrm{NO}_{3}\right)_{2}\right.$ and $\mathrm{NaCl}$ with purity $\geq 95 \%$ ) and the DMSO (purity $\geq 97 \%$ ) were all purchased from Sigma-Aldrich (St. Louis, MO, USA). Ononitol was purchased from Carbosynth (UK). D-(-)bornesitol standard, which was not commercially available, has been obtained from prof. Lahuta Lesław from University of Warmia and Mazury, Poland. The yeast (Saccharomyces cerevisiae) was obtained from Sigma-Aldrich (Steinheim, Germany). Ultra-pure water was produced using a Milli-Q water system (Millipore, Bedford, MS, USA). The SPE columns CHROMABOND ${ }^{\circledR} \mathrm{C} 18$ ec and CA (cellulose acetate membrane) membrane filter $(0.22 \mu \mathrm{m} \times 25 \mathrm{~mm})$ were both purchased from Macherey-Nagel (Düren, Germany).

The alfalfa seeds (Medicago x varia Martyn) were procured from Plantico Waganiec and then grown without nutrients of fertilizers in the laboratory of Interdisciplinary Centre of Modern Technologies, at Nicolaus Copernicus University, Torun, Poland. The seeds were deposed in Petri dishes on filter paper and grown at $22{ }^{\circ} \mathrm{C}$ (three repetitions of dishes for each treatment, and control dishes). During each day $(24 \mathrm{~h})$, they were exposed to the light for $18 \mathrm{~h}$ and kept into the dark for $6 \mathrm{~h}$. The seedlings have been watered every 2 days with tap water containing the next elicitors: $\mathrm{AgNO}_{3}$ (100 mg/L), $\mathrm{Zn}\left(\mathrm{NO}_{3}\right)_{2}(200 \mathrm{mg} / \mathrm{L})$ and $\mathrm{NaCl}(50 \mathrm{mM}$, which is the equivalent of $292 \mathrm{mg} / \mathrm{L}$ ). The control samples were watered with normal tap water. After a growth period of 8 days, the alfalfa seedlings were harvested (both the stems and leaves together), dried in oven at $40{ }^{\circ} \mathrm{C}$, and then milled using a laboratory mill.

The alfalfa used to evaluate the influence of cultivation place, originating from different countries was either bought from shops or harvested. The samples purchased from shops were sold as organic product for human or pet consumption. 
The cultivated samples were grown in their natural environment as feed for animals, without using without pesticides or fertilizers. Please find details about cultivation area of each sample, together with climate and meteorological information of given country in Table 1.

In case of the sample originating from Serbia, a voucher specimen for plant material (Medicago x varia Martyn 1793, "NS-Medija" No-2-1484) was confirmed and deposited at the Herbarium of the Department of Biology and Ecology (BUNS Herbarium, Faculty of Natural Sciences), at University of Novi Sad.

Another set of samples, used for seasonal investigation, were represented by alfalfa cultivated in two countries: Poland (Grosz Marian Oczkowski (Zalesie-Szubin, Kuyavian-Pomeranian Voivodeship)) and Romania (Călăraşi Gară village, Cluj County). The samples were harvested in 2 different seasons: May and August 2017. In both cases the plants were cultivated as animal feed and no pesticides or fertilizers were used. For all cultivated samples, aerial parts of the alfalfa plants were placed in a crate with perforated bottom, in order to ensure a free air flow. Drying of plants was performed naturally, on draft and in dark, until moisture content was about $10 \%$. Finally, dried plant material was powdered in a mill.

\section{Evaluation of seedlings growing under elicitation}

First, a number of 30 seedlings were randomly selected from each Petri dish - for both elicited and control samples. They were then used for biomass evaluation, for the measurement of roots length and for counting the root branches. Germination was verified after $36 \mathrm{~h}$ and at the end of growing period. Cotyledons chlorophyll content (chlorophyle A, chlorophyle $\mathrm{B}$, and total chlorophyle) under each treatment and control was evaluated as well. Three different replicates were prepared for each case. For the measurement of chlorophylls, $20 \mathrm{mg}$ of cotyledon material was weight into an Eppendorf, frozen by holding it together with the Eppendorf into liquid nitrogen, and well macerated using a ball mill. In the next step, $1 \mathrm{~mL}$ DMSO was added to each Eppendorf containing macerated cotyledons, vortexed for $1 \mathrm{~min}$, and centrifuged at $10,000 \mathrm{rpm}$ at $10{ }^{\circ} \mathrm{C}$ for $10 \mathrm{~min}$. The supernatant was removed, then another $1 \mathrm{~mL}$ of DMSO has been added to the pellet and a re-extraction process was made. Both supernatants obtained were put together and the obtained extract was interrogated by measuring its optical absorbance. A NanoDrop 2000C Spectrophotometer (Thermo Scientific, UK) was used for the absorbance measurement at 645 and $663 \mathrm{~nm}$ wavelengths. DMSO was used as a blank to calibrate the instrument by setting the value 0 of absorbance. The calculations were realized using Arnon's equations. Mann-Whitney test was performed in order to check the significance level between each group, compared with the control. In Table 2, plant growing development evaluation under the treatment with each elicitor and control is presented.

\section{Sample extraction, purification, and selective separation}

Accelerated solvent extraction (ASE) has been performed using a Dionex ASE 350 system (Thermo Scientific, Waltham, MA, USA), equipped with an auto-sampler carousel and a collection tray that can perform the sequential extraction of up to 24 samples. For each sample $0.5 \mathrm{~g}$ of grounded vegetal powder was introduced in a $10-\mathrm{mL}$ stainless steel extraction cell and then extracted using water as a solvent. The extraction process was performed at a temperature of $50{ }^{\circ} \mathrm{C}$, a pressure of $10 \mathrm{MPa}$, during three cycles (of $18 \mathrm{~min}$ each). The solution obtained after the extraction process was filtered through a CA membrane $(0.22 \mu \mathrm{m} \times 25 \mathrm{~mm})$ and after that eluted through a column filled with $\mathrm{CHROMABOND}{ }^{\circledR} \mathrm{C} 18 \mathrm{ec}$, which has been previously activated with $3 \mathrm{~mL}$ of methanol and equilibrated with $3 \mathrm{~mL}$ of water. The resulted solution containing a mixture of sugars, sugar alcohols, and cyclitols was then subjected to fermentation, for $48 \mathrm{~h}$, at $37^{\circ} \mathrm{C}$, under stirring, in dark, by using yeast $(0.125 \mathrm{mg} / \mathrm{g}$ of dry plant). After this yeast treatment, the samples were centrifuged at $10,000 \mathrm{rpm}$ at $10^{\circ} \mathrm{C}$ for $10 \mathrm{~min}$ and filtered through CA membrane. The obtained solution was finally loaded onto a column with Dowex 1-X8 anion exchange resin $100-200-$ mesh $(15 \times 1.5 \mathrm{~cm})$ in the hydroxide ion form, to remove the remaining sugars traces and sugar alcohols (which are not affected by this type of fermentation).

Derivatization with TMSI was used to facilitate the GC-MS analyses. Derivatization is an important step meant to transform the cyclitols (which are nonvolatile) in semivolatile components, by binding them to silyl groups. The derivatization can sometimes serve also in extract purification, once other nonvolatile existing components are not going to be included into the analysis (Ratiu et al. 2019, 2020). Consequently, for GC-MS analyses, $200 \mu \mathrm{L}$ of purified solution was mixed with $10 \mu \mathrm{L}$ allo-inositol (considered as internal standard (IS), with a purity $\geq 95 \%$ ) and then evaporated to dryness using a rotary evaporator. The dried sample was then derivatized with a mixture of TMSI and pyridine $(1: 1, \mathrm{v} / \mathrm{v})$ at $80^{\circ} \mathrm{C}$ for $3 \mathrm{~h}$, and $1 \mu \mathrm{L}$ of each sample was injected in the GC injection port. Each sample was injected in triplicate. For quantification, stock solutions of pure standards with concentration of $1 \mathrm{mg} / \mathrm{mL}$ were prepared in water. Each standard solution was diluted to six appropriate concentrations and $150 \mu \mathrm{L}$ of each solution was mixed with $10 \mu \mathrm{L}$ of IS, evaporated to dryness and derivatized with a mixture of TMSI and pyridine (1:1, v/v). A volume of $1 \mu \mathrm{L}$ was injected in the GC-MS port. Three replicates were injected for each concentration. The internal 


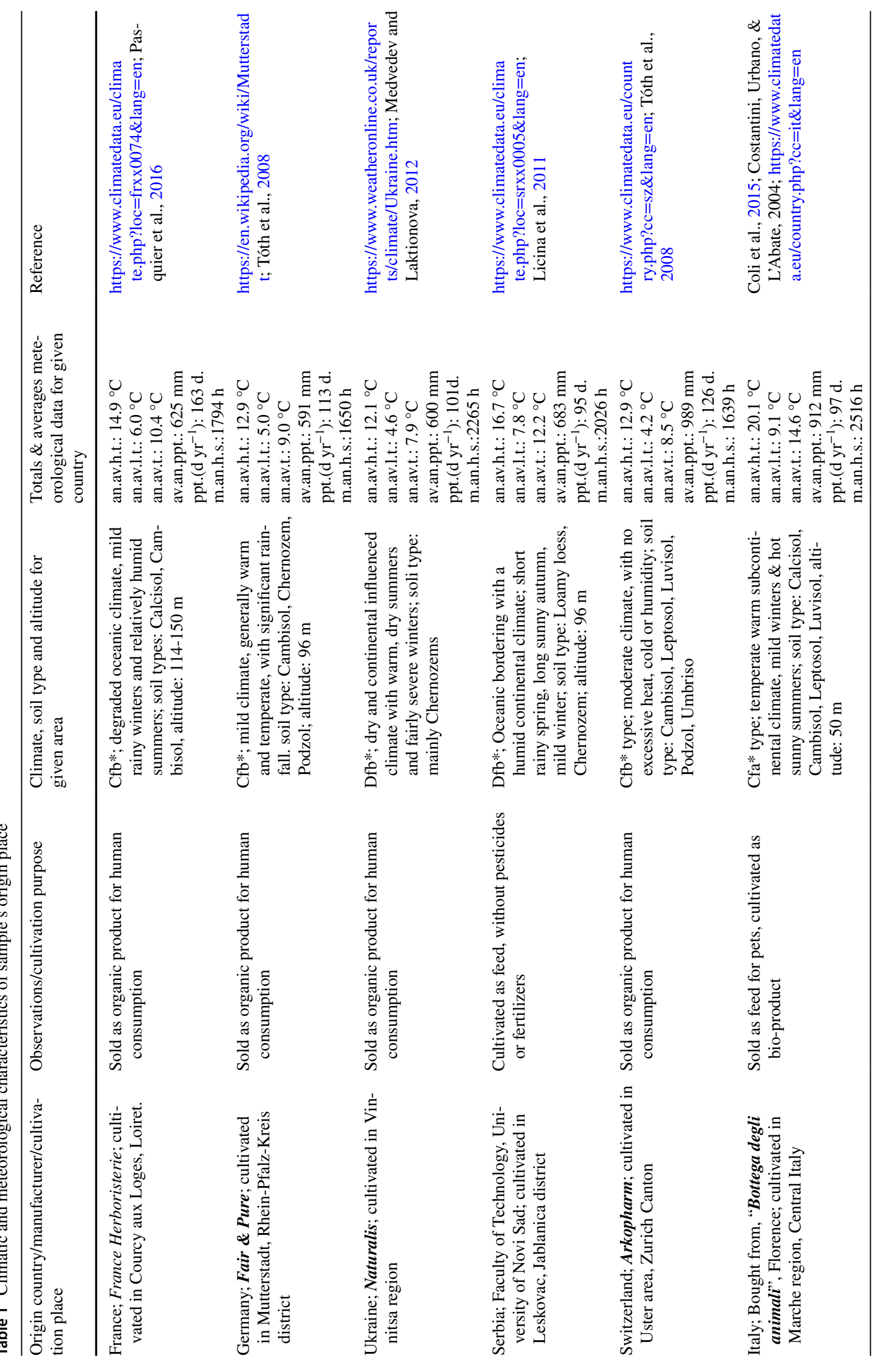




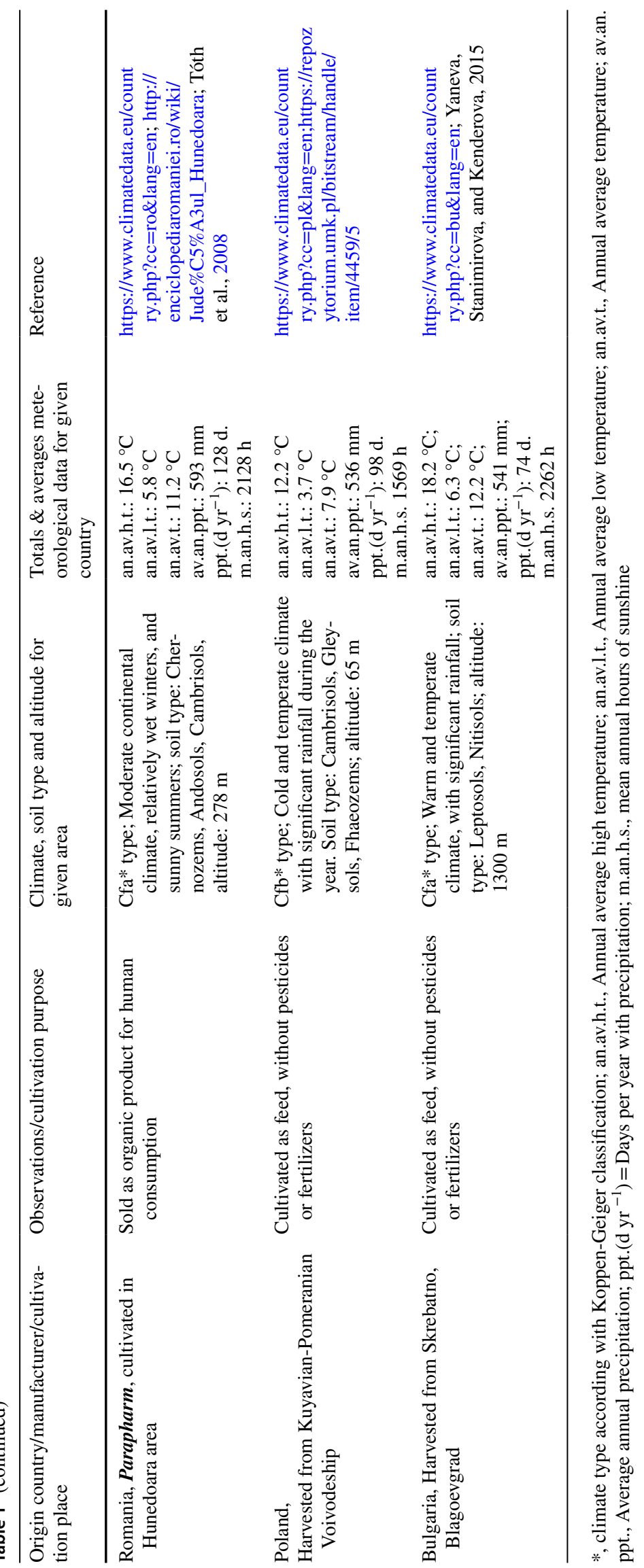

望 Springer 
Table 2 Seedlings growing evaluation under elicitation

\begin{tabular}{|c|c|c|c|c|c|c|c|c|}
\hline & \multicolumn{3}{|c|}{ Chlorophyll type $\left(\mathrm{mg}^{*} \mathrm{l}^{-1}\right)$} & \multicolumn{2}{|c|}{ Germination \% } & \multirow[t]{2}{*}{ Biomass $\bullet$ (mg) } & \multirow[t]{2}{*}{ Root length $\bullet(\mathrm{cm})$} & \multirow{2}{*}{$\begin{array}{l}\text { Number of } \\
\text { root branches } \\
\text { - }\end{array}$} \\
\hline & Chlorophyll A & Chlorophyll B & Total chlorophyll & $36 \mathrm{~h}$ & 8 days & & & \\
\hline Control & $6.21 \pm 0.268$ & $0.752 \pm 0.016$ & $12.486 \pm 0.625$ & $46.3 \pm 4,6$ & $78 \pm 2.4$ & 546.9 & $1.74 \pm 0.10$ & $2.8 \pm 0.6$ \\
\hline $\mathrm{AgNO}_{3}$ & $7.99 \pm 0.683$ & $0.809 \pm 0.064$ & $15.779 \pm 1.363^{*}$ & $38.3 \pm 1.7^{*}$ & $70.7 \pm 1.6^{*}$ & $555.6^{\mathrm{a}}$ & $2.6 \pm 0.25^{\mathrm{b}}$ & $3.7 \pm 0.6^{\mathrm{a}}$ \\
\hline $\mathrm{Zn}\left(\mathrm{NO}_{3}\right)_{2}$ & $6.406 \pm 0.459$ & $0.626 \pm 0.037^{*}$ & $12.72 \pm 0.938$ & $29.6 \pm 2.8^{*}$ & $52.3 \pm 2 *$ & $546.3^{\mathrm{a}}$ & $1.79 \pm 0.2^{\mathrm{a}}$ & $3.1 \pm 0.7^{\mathrm{a}}$ \\
\hline $\mathrm{NaCl}$ & $8.406 \pm 0.199 *$ & $0.752 \pm 0.055$ & $16.899 \pm 0.445^{*}$ & $10.6 \pm 2.5^{*}$ & $71 \pm 2.1^{*}$ & $511.2^{\mathrm{a}}$ & $1.25 \pm 0.15^{\mathrm{b}}$ & $2.4 \pm 0.5$ \\
\hline
\end{tabular}

-, 30 seedlings randomly selected were used for evaluation; \#, total value for 30 seedlings; ${ }^{\mathrm{a}}=$ correlation significant at the 0.05 level; ${ }^{\mathrm{b}}=$ correlation significant at the 0.01 level

ratios (defined as peak area of analyte/peak area of IS) were calculated for each concentration of standards, and calibration curves were built by plotting internal ratios versus concentrations for each standard. The concentration range for each standard is presented in Table 3.

\section{Gas-chromatographic analysis}

GC-MS analyses were finally performed in order to identify and quantify the cyclitols obtained. The analysis was realized using an AutoSystem XL GC-MS, including a gas chromatograph coupled with a TurboMass mass spectrometer (both manufactured by Perkin Elmer, Norwalk, $\mathrm{CT}$, USA) using as carrier gas $\mathrm{He}$ at $1 \mathrm{~mL} / \mathrm{min}$. A capillary column type RTX-5MS $(30 \mathrm{~m} \times 0.25 \mathrm{~mm} \times 0.250 \mu \mathrm{m})$ (produced by Restek, Bellefonte, PA, USA) was used. Temperature of the GC oven was programmed as follows: an initial temperature of $90^{\circ} \mathrm{C}$ was held for $1 \mathrm{~min}$ and then temperature ramped to $300{ }^{\circ} \mathrm{C}$ at a rate of $10.0{ }^{\circ} \mathrm{C} / \mathrm{min}$ and was then kept for $5 \mathrm{~min}$ at this temperature. Injector temperature was $260{ }^{\circ} \mathrm{C}$ and all injections were made in the split mode, using a split flow of 1:25. Mass spectrometer MS was operated as follow: ion source temperature $280{ }^{\circ} \mathrm{C}$; ionization energy $70 \mathrm{eV}$ (electron impact ionization); scanning range $35-650 \mathrm{~m} / \mathrm{z}$. The acquisition of chromatographic data was performed by using TurboMass (Perkin Elmer) and mass spectrum library NIST 2005 (Gaithersburg, USA). All calibration data: average of the peak retention time (RT), calibration equations using peaks area for GC/MS detection, linearity presented as a correlation coefficient (R2) of the calibration curves, limits of detection (LOD) and quantification (LOQ), precision (RSD) as a relative standard deviation estimated for peak areas are presented in Table 3.

Retention indexes were calculated based on Kovats retention index equation and determined using a mix of n-alkane standards from C9 to C27. The accuracy was evaluated as a recovery at each concentration over $80-120 \%$ of the analyte range concentrations. The results showed that average recovery at different level of concentration ranged from 95.3 to $98.1 \%$ and RSD was 3\%. The calibration curves' parameters have shown good correlation coefficients, between $R=0.9979$ and $R=0.9997$.

No unexpected hazard or risk could be associated with the reported work.

\section{Statistical approaches}

Correlation analysis, hierarchical clusters analysis, and Mann-Whitney U test was performed by using IBM SPSS statistical software, package version 21. Bar graphs of components were created in Microsoft Excel 2016, and Microsoft Power Point 2010 was used to label and combine the figures.

Table 3 Calibration data including: retention time (RT), retention index (RI), calibration equations, linearity coefficient (R2), limit of detection (LOD), limit of quantification (LOQ) and precision (RSD)

\begin{tabular}{llllllrrr}
\hline Identified targets & RI & RT (min) & Calibration equation & $\mathrm{R}^{2}$ & RSD $(\%)$ & LOD ng/mL & $\begin{array}{c}\text { LOQ ng/mL } \\
\text { Concentration } \\
\text { range }(\mathrm{mg} / \mathrm{mL})\end{array}$ \\
\hline D-Pinitol & 1861 & 12.90 & $\mathrm{y}=0.1764 \mathrm{x}-0.4197$ & 0.9994 & 1.37 & 6.78 & 20.55 & $2.5 \times 10^{-4}-0.4$ \\
D-Chiro-inositol & 1985 & 14.13 & $\mathrm{y}=0.19223 \mathrm{x}-0.0592$ & 0.9996 & 2.17 & 3.56 & 10.80 & $1.25 \times 10^{-4}-0.05$ \\
Ononitol & 1992 & 14.23 & $\mathrm{y}=0.0134 \mathrm{x}-0.1991$ & 0.9979 & 0.19 & 25.13 & 76.16 & $125 \times 10^{-4}-0.5$ \\
Bornositol & 2035 & 14.65 & $\mathrm{y}=0.019 \mathrm{x}-0.0382$ & 0.9986 & 0.10 & 5.75 & 17.44 & $20 \times 10^{-4}-0.25$ \\
Scyllo-inositol & 2058 & 14.87 & $\mathrm{y}=0.0772 \mathrm{x}-0.0262$ & 0.9997 & 0.69 & 4.05 & 12.27 & $5 \times 10^{-4}-0.1$ \\
Myo-inositol & 2120 & 15.45 & $\mathrm{y}=0.14361 \mathrm{x}-0.0079$ & 0.9993 & 1.77 & 9.72 & 29.44 & $1.25 \times 10^{-4}-0.08$ \\
& & & & & & & &
\end{tabular}




\section{Results and discussion}

\section{Elicitors' influence on cyclitols production}

Visual inspection of seedlings allowed us to observe that the plants elicited with $\mathrm{AgNO}_{3}$ grew up better compared with others, shown stronger and more branched roots, while the leaf color was greener than in the control samples. Samples watered with $\mathrm{Zn}\left(\mathrm{NO}_{3}\right)_{2}$ solution grew slightly better than controls, but the roots and leaf characteristics were similar with those of controls. In contradiction with the first two categories, the samples treated with $\mathrm{NaCl}$ showed weaker germination, smaller seedlings presenting a slight burning appearance, low branched roots and a dark green leaf color in comparison with controls. The data related to seedlings growing and development is presented in Table 2. Moreover, in Fig. 1 (lower part) a picture of elicited seedlings plates in comparison with control can be observed. In contrast with mature plants cultivated in different countries, in which 4 up to 6 cyclitols were identified, in seedlings just three of them (D-pinitol, myo-inositol and D-chiro-inositol) were detected. In Fig. 1 (upper part) the detected quantities of cyclitols identified in alfalfa seedlings are presented. The obtained results highlighted that plant elicitation with $\mathrm{NaCl}$ significantly increases the amount of all identified cyclitols.

As stated before, inositol's formation is directly connected with ionic and osmotic stress. Myo-inositol is the unique natural occurring cyclitol and the others are derivatives of it. Cyclitols synthesis in plants occurs from glucose to myoinositol in three major steps. After that from myo-inositol the other cyclitols are formed, as presented in Fig. 2. Firstly, the synthesis of myo-inositol 1-phosphate from glucose occurs and from this free myo-inositol is generated (because myo-inositol phosphate $+\mathrm{H}_{2} \mathrm{O} \rightleftharpoons$ myo-inositol + phosphate) .
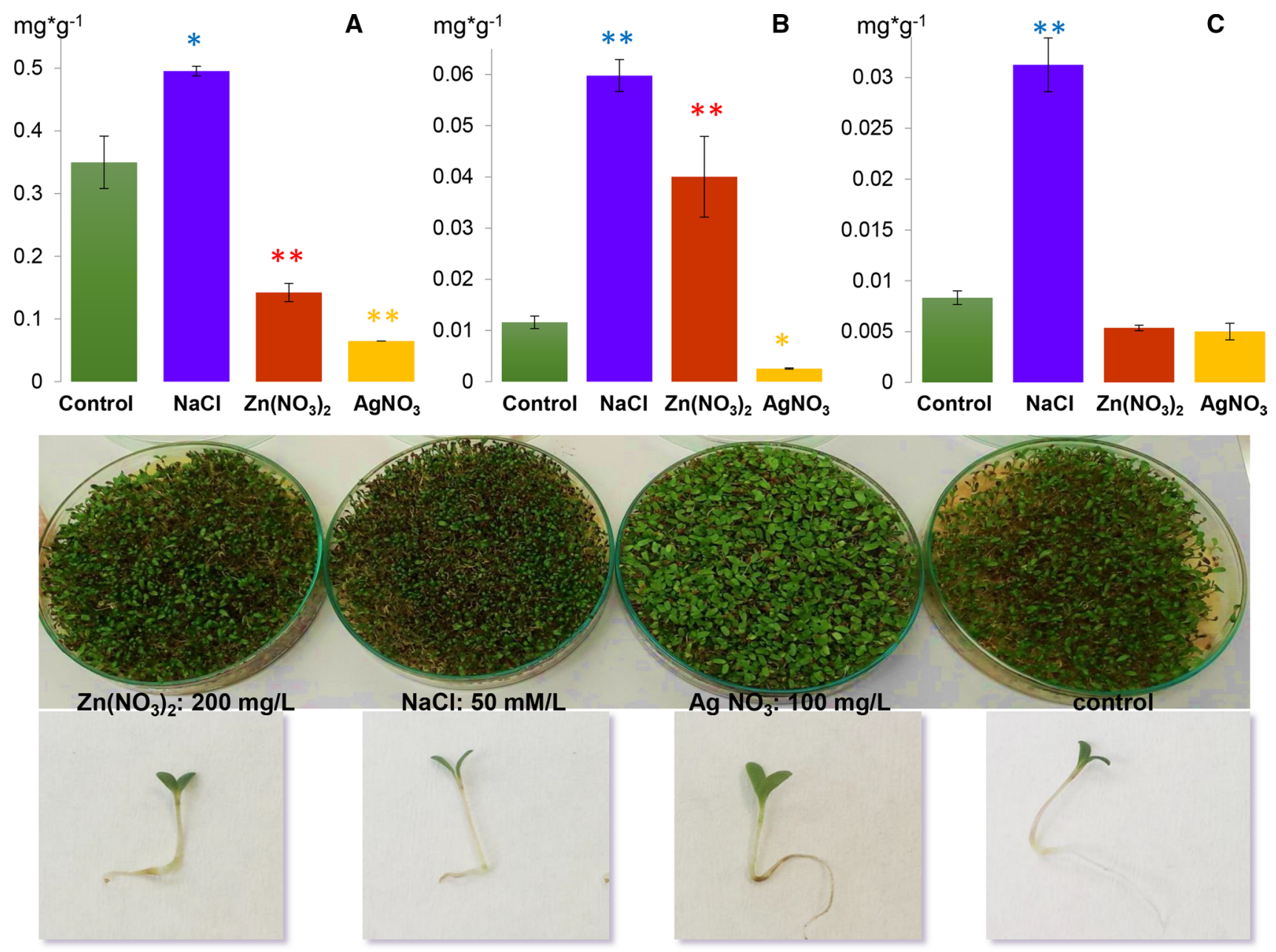

Fig. 1 The quantities of cyclitols detected in seedlings (upper part) and pictures of growing plates containing the plants treated with elicitors after 8 days of growing period (lower part), where $\mathrm{A}=\mathrm{D}$-pinitol,
$\mathrm{B}=$ myo-inositol, $\mathrm{C}=\mathrm{D}$-chiro-inositol; $*=$ correlation significant at the 0.05 level; $* *=$ correlation significant at the 0.01 level 


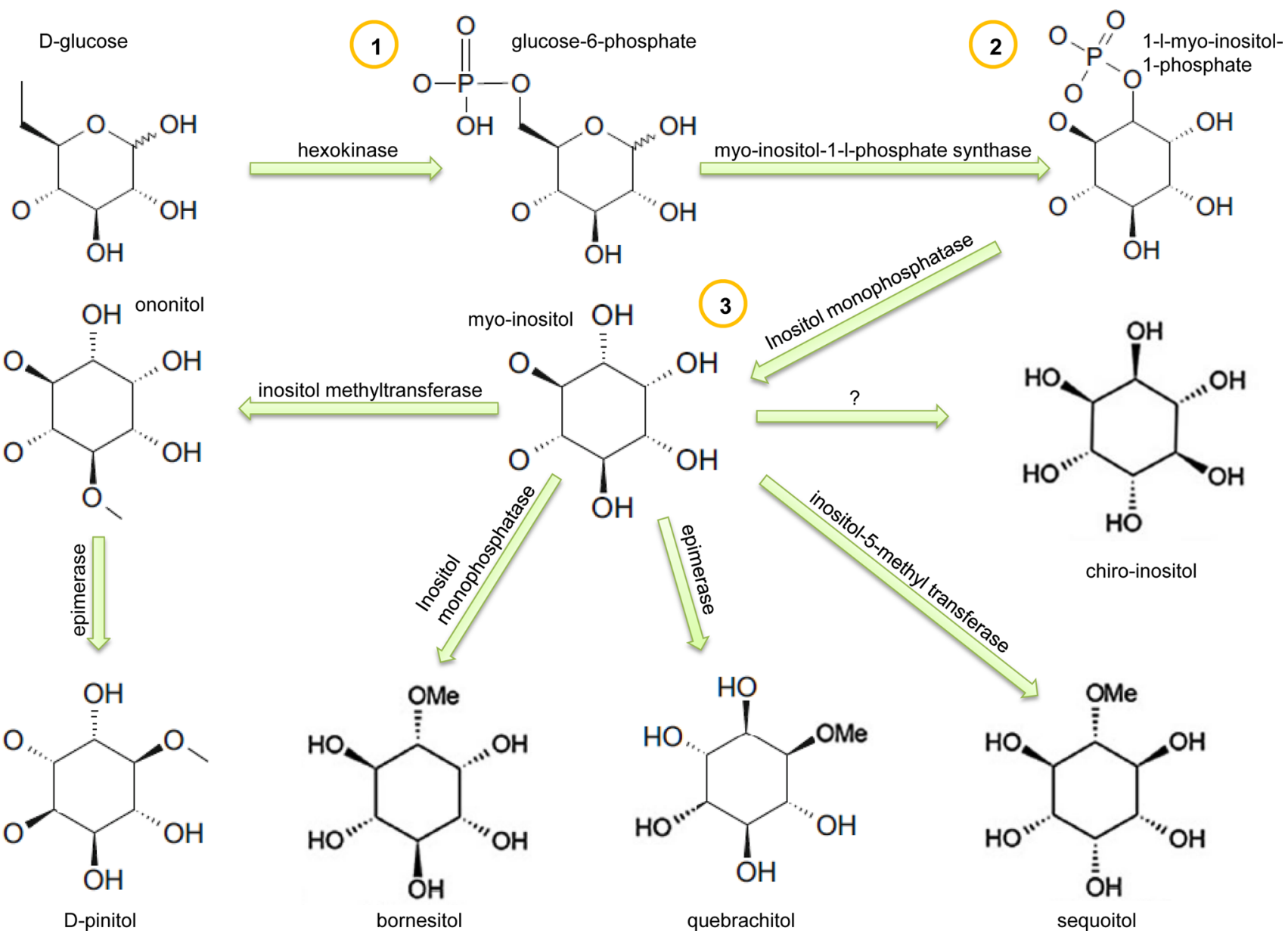

Fig. 2 Schematic representation of cyclitols synthesis in plants

In the second step, methylation of myo-inositol takes place, resulting in the formation of ononitol. Finally, ononitol is epimerized one more time and pinitol is generated, through the action of two enzymes, inositol-Omethyltransferase and ononitol epimerase, respectively (Sengupta et al. 2008).

Pinitol is a well-known osmoprotectant found in many plants (Sengupta and Majumder 2010). Myo-inositol 1-phosphate synthesis showed that enzymatic activity is properly realized even in large salt concentrations (Sengupta et al. 2008). Among the cyclitols, myo-inositol was specifically found to be stockpiled in halophytes, acting as an osmolyte (Sengupta and Majumder 2010) while its derivatives have the ability to regulate salt stress response by serving as compatible solutes and signaling molecules (Kido et al. 2013). Our results confirmed that cyclitols are more accumulated in samples elicited with $\mathrm{NaCl}$. Moreover, once inositol methyl transferase, which methylates myo-inositol into pinitol, is upregulated in the same conditions as inositol, then 1-phosphate synthase indicates that cyclitols' synthesis and their conversion to pinitol are the key processes connected with the effect of salt on the seedlings.
In the seedlings elicited with $\mathrm{Zn}\left(\mathrm{NO}_{3}\right)_{2}$ only the amount of myo-inositol increased, approximatively four times. In contrast with myo-inositol, in case of D-pinitol and D-chiro-inositol the obtained amounts were lower in elicited seedlings in comparison with controls. Regarding D-chiro-inositol, its quantity decreased in samples treated with this elicitor. These findings suggest that it is difficult to decide whether $\mathrm{Zn}\left(\mathrm{NO}_{3}\right)_{2}$ is a stressing agent able to trigger increasing of cyclitols inside alfalfa plants. Due to the rising amount of myo-inositol, we could state that yes, this is the case. What about the decreasing amount of the other two cyclitols? It was stated that myo-inositol is the only one cyclitol naturally occurring in plants, while the others are its derivatives (Al-Suod et al. 2017). According to our results, myo-inositol occurrence is stimulated by $\mathrm{Zn}\left(\mathrm{NO}_{3}\right)_{2}$; however, it seems that the methylation of myo-inositol, which should result into formation of the other cyclitols, is slowing down.

Regarding the samples elicited with $\mathrm{AgNO}_{3}$, the quantities of all three cyclitols detected decreased, compared with the control lot. This was not very surprising, once it is 
known that the secondary metabolites are generated when the growing process is inhibited then the carbon surplus is going to be fixed predominantly to secondary metabolites (Bennett and Wallsgrove 1994). After the visual inspection of the seedlings and the evaluation of growing parameters under elicitation (Table 2), it was obvious that the samples elicited with $\mathrm{AgNO}_{3}$ grew up better that plants elicited with $\mathrm{NaCl}, \mathrm{Zn}\left(\mathrm{NO}_{3}\right)_{2}$, and better than controls as well. Therefore, we can say that $\mathrm{AgNO}_{3}$ elicitation favors seedlings' development and that in the same time the cyclitols production is slowing down.

\section{Seasonal impact on cyclitols' production}

Two countries, Poland and Romania, have been selected for evaluating the seasonal impact. The quantities of cyclitols in samples originated from these two countries were significantly different for the two investigated seasons, as presented in Fig. 3a. The differences between the quantities of cyclitols detected in plants harvested in August were statistically significant at the 0.05 level when compared with those cultivated in May. Moreover, almost double amounts of each cyclitol were found in samples harvested in August, compared with those collected in May, for both investigated countries. The highest quantity of cyclitols was detected in samples from Romania, while ononitol was detected just in samples coming from this country. We assumed that these differences are closely connected with the climate.

Meteorological information was compared for Season 1 (March-May) and Season 2 (June-August) for both countries, in order to find differences and correlations between: average temperatures recorded, number of days with precipitation, number of full sunny days, number of cloudy days, number of windy days, relative humidity and total amount of precipitation. Observing the values of these parameters we found multifarious disparities between countries. Regarding
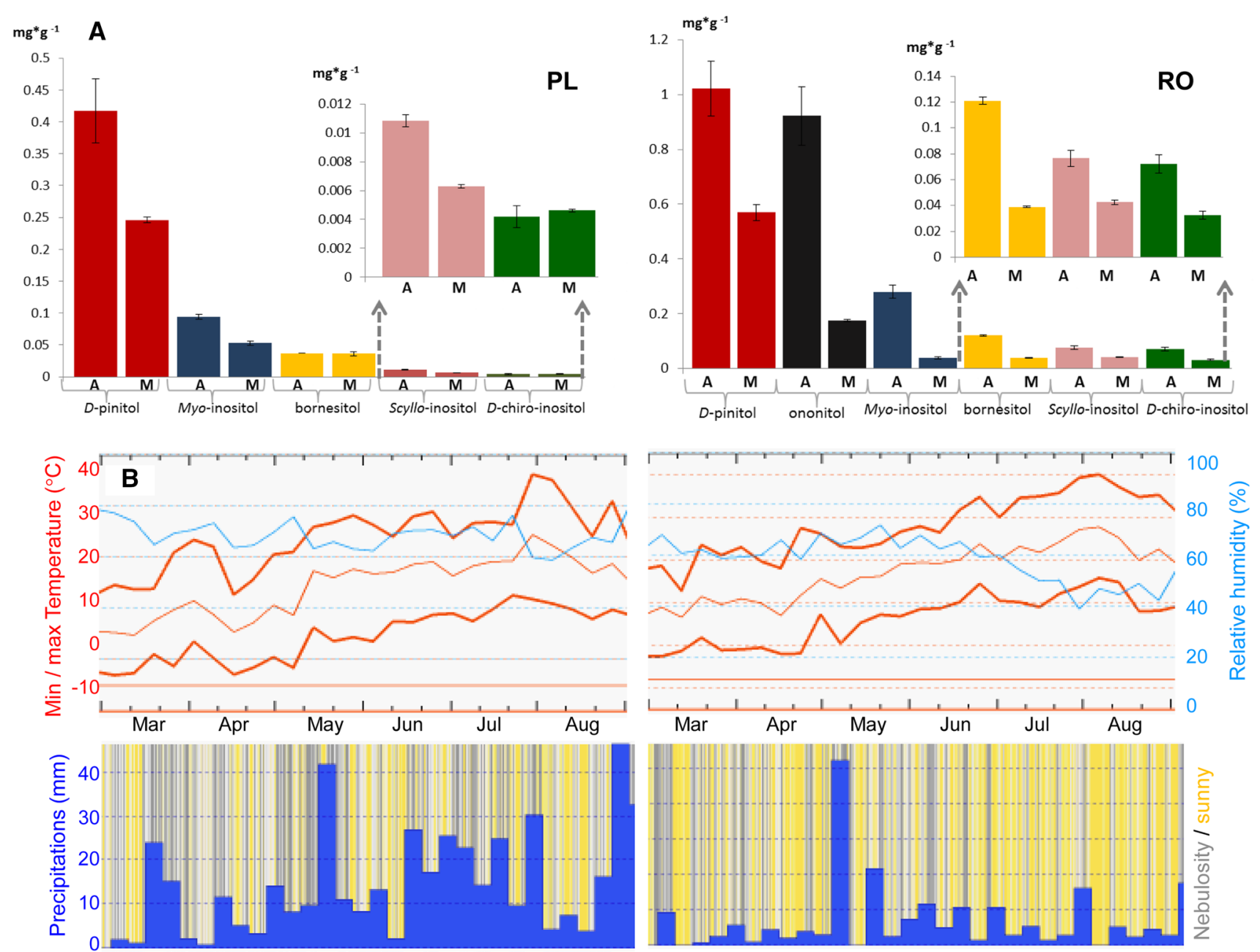

Fig. 3 The amount of cyclitols detected in samples cultivated in two different seasons, August (A) \& May (M) in Poland (PL) and Romania (RO)- part A and a general view of meteorological data recorded for the period March-August 2017- part B. The information presented in part B was adopted and processed from meteoblue weather website www.meteoblue.com 
medium temperatures for Season 1, there were recorded $9.6{ }^{\circ} \mathrm{C}$ in Poland and $12.3{ }^{\circ} \mathrm{C}$ in Romania, while for Season $2,19.6{ }^{\circ} \mathrm{C}$ was registered in Poland and $22.6{ }^{\circ} \mathrm{C}$ in Romania. The relative humidity was slightly higher in Poland than in Romania in both seasons. The number of full sunny days in Romania (34 in Season 1 and 65 in Season 2) exceeds that registered in Poland (28 in Season 1 and 38 in Season $2)$. The total amount of precipitation was higher in Poland (144 $\mathrm{mm}$ in Season 1 and $218 \mathrm{~mm}$ in Season 2) than in Romania (115 mm in Season 1 and just $70 \mathrm{~mm}$ in Season 2). The total number (Season 1 plus Season 2) of cloudy days (17) and windy days (15) was lower in Romania than in Poland (33 cloudy days and 33 windy days). All this information was adopted and processed from meteoblue weather website (www.meteoblue.com) with the permission granted in 12 October 2018, through Ticket\#2018101210000121. A schematic diagram presenting a general view of temperature, quantity of precipitation, relative humidity and sunny versus cloudy days recorded for the period March to August 2017, in both countries is given in Fig. 3 b.

A Pearson product-moment correlation was conducted to investigate the relationship between: all the abovementioned factors, total amount of cyclitols and also the amount of each individual cyclitol, for both approaches: the investigated seasons and for samples cultivated in different countries. Part A of Fig. 4 is related to seasonal impact evaluation, while part B to the cultivation place' influence. In case of seasonal investigation (Fig. 4a), the total amount of cyclitols was strongly positively correlated $(r=0.957$, $p=0.01$ ) with the number of sunny days and strongly negatively correlated $(r=-0.989, p=0.01)$ with humidity. Moreover, the total amount of cyclitols was positively correlated $(r=0.953-0.999, p=0.05)$ with the quantities of all other cyclitols detected, excepting myo-inositol. The humidity was strongly negatively correlated with each individual cyclitol ( $r=-0.957$ to $-0.985, p=0.01)$, while the number of full sunny days were positively correlated just with the amount of D-pinitol ( $r=0.963, p=0.01)$. These findings clearly indicated that humidity and numbers of sunny days express more variability that other does with the total amount of cyclitols detected and with each individual one as well. Moreover, according to the correlation results it appears that the lack of humidity and the sun shine favors the occurrence of cyclitols, especially of D-pinitol. We assume that the differences in cyclitols' quantities obtained in the two investigated seasons can be given by the number of sunny days, which were obviously more numerous in Season 2 compared with Season 1, in both countries. In case of the

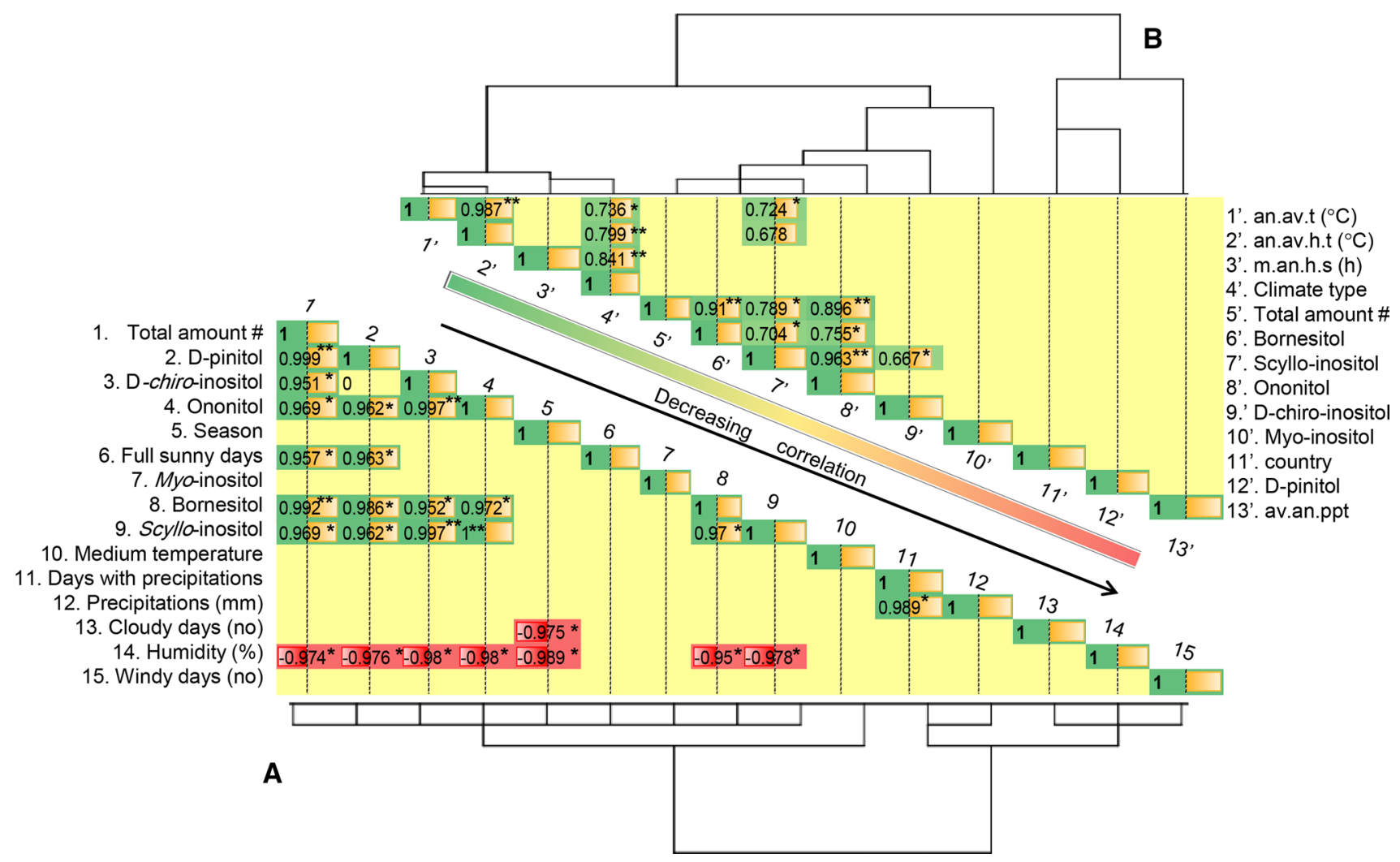

Fig. 4 Correlation and hierarchical clusters analyses of investigated variable, where: $* *=$ correlation significant at the 0.01 level; $*=$ correlation significant at the 0.05 level; $\#=$ total amount of cyclitols detected; an.av.t. $=$ annual average temperature; an.av.h.t. $=$ annual average high temperature; m.an.h.s. = mean annual hours of sunshine, ppt. $($ dyr $)=$ days per year with precipitation 
differences between cyclitols detected in samples originated from the two mentioned countries, we suppose that, besides the meteorological factors, there are others that can influence the obtained amounts. The topic of geographical distribution will be discussed in the following part of this paper.

Nevertheless, hierarchical clusters analysis grouped the variables involved in Fig. $4 \mathrm{a}$ in three main clusters. The variables 1-9 were fused together in one cluster with similar distance level, while those numbered from 4 to 10 presented similarities with higher distance level. As expected the variables 11 and 12 (corresponding to the number of days with precipitations \& the amount of precipitations were close located) and near them the last three clusters were segregated (13-15). Consequently, we can conclude that the dendrogram related to Fig. 4a is highlighting in an objective manner the relationship between the investigated variables.

\section{The influence of cultivation place onto the cyclitols amount}

The total amount of cyclitols detected in samples originated from different countries was significantly different, ranging from $0.3347 \pm 0.0039 \mathrm{mg} \mathrm{g}^{-1}$ (Germany) to $3.2036 \pm 0.399 \mathrm{mg} \mathrm{g}^{-1}$ (Serbia). The quantities of each cyclitol were calculated and presented in Fig. 5, together with standard deviation, which represents a mean of three replications. The dendrogram related to the quantified cyclitols (presented in the upper part of Fig. 5) has separated D-pinitol (the target detected in the highest amount) by the other cyclitols, which fused together in two clusters with almost similar distance levels. Hierarchical cluster analysis with respect of the total quantity detected in samples originated from the investigated countries grouped the countries noted from 1 to 6 together in a cluster with similar distance level. At higher distance level were fused the samples corresponding to countries 7 and 8 , while the last one, no 9
(Serbia), was positioned at the opposite site as a separate cluster with the highest distance level.

As other articles stated before (Al-Suod et al. 2019b) our results confirm as well that in alfalfa plant D-pinitol is the most abundantly occurring cyclitol, while scyllo-inositol is found in the lowest amount. It can be observed in Fig. 5 that ononitol did not appear in the samples originated from France, Germany, Switzerland and Poland, all four mentioned countries having the same climate type ( $\mathrm{Cfb}$ (Temperate oceanic climate), according with Koeppen-Geiger classification), as presented in Table 1. Moreover, scyllo-inositol was absent in samples originated from France, Germany and Bulgaria.

In the attempt to investigate which factors can influence the cyclitols' accumulation in alfalfa, in case of plants cultivated in their natural environment, most of them as bio-products for human consumption grown without pesticides or fertilizers, a Pearson correlation analysis were was used. As presented in Fig. 4b, the relationships between climate type, meteorological characteristics, total amount of cyclitols, and individual amount of cyclitols detected in samples originating from nine different countries included into the study were investigated. The correlation matrix presented in Fig. 4b highlighted positive correlation only between cyclitols, their total amount, as well as some correlation related to climatic characteristics, but no correlation related to climate type or cultivability place was found, neither with the total amount of cyclitols detected, nor with the individual amount of cyclitols. Hierarchical clusters analysis with respect of Fig. 4b grouped correct the investigated variables according with their main characteristics; consequently three main clusters with different distance level were formed.

Nevertheless, our results highlighted that detected quantities of cyclitols in samples originated from different countries are obviously different. Considering the

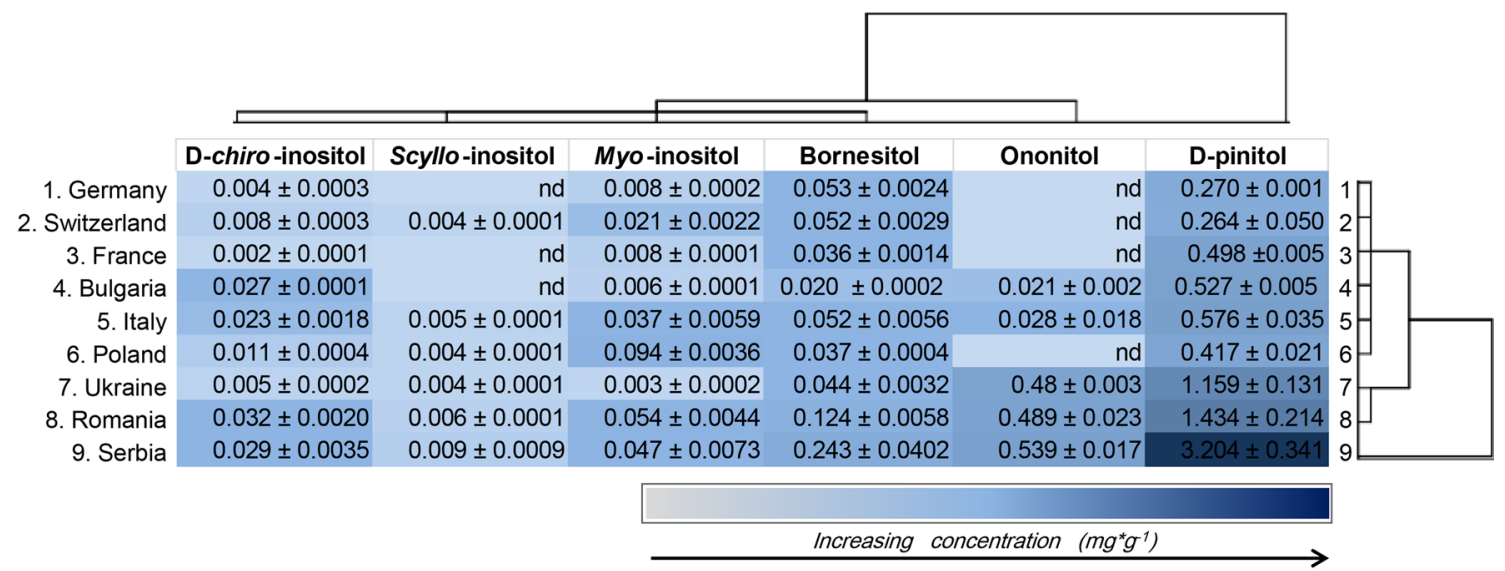

Fig. 5 Heat map presenting the quantities of cyclitols detected in samples from different countries, where nd-not detected 
above-mentioned ideas, we have investigated other possible factors that could affect the amounts of cyclitols. We supposed that one factor can be the soil type. By investigating each target, it was observed that D-pinitol is the responsible compound for the discrepancies of total amount measured in samples originated from different countries, while the quantities of the others cyclitols were comparable. As discussed before, the salinity level plays an important role in cyclitols occurrence in plants, and it is especially connected with D-pinitol deposition. In addition, in the "Seasonal impact on cyclitols' production" section we discussed that a positive correlation between the number of sunny days and D-pinitol amount was found.

Soil salinity (the accumulation of soluble salts in soil) may occur where irrigation practices have caused a rise in water-tables, ringing saline groundwater within reach of plant roots. Serbia, Romania and Ukraine (which belonged to the former CAP (Common Agricultural Policy organization) are known as countries in Europe with tradition in cultivation of land, having fertile soils as chernozem, which can easily accumulate soluble salts. Nevertheless, before the major sociopolitical changes in the year 1989 the soil of the mentioned countries has been extensively exploited for agricultural purposes and thus irrigation systems were used. The evidence of soil degradation and salinization caused by agricultural activities in the mentioned countries was highlighted in some research and review articles (Licina et al. 2011; Medvedev and Laktionova 2012; Virto et al. 2015). In samples originated from Serbia, Romania and Ukraine we found the highest amount of cyclitols. By observing the climate characteristics (Table 1), it can be noticed that the duration of the sunshine is higher in the mentioned countries as compared with others, except for Italy and Bulgaria.

The lowest amount of cyclitols, found in alfalfa samples originated from Bulgaria, can be because of the soil type. The Leptosols and Nitisols present in the cultivation area are limited rooting and stoniness soils, characterized by shallow soil over bedrock, mainly constituted from calcareous material (Costantini et al. 2004; Tóth et al. 2008). Salinity phenomena are less probable here, because calcic soils have no ability for soluble salts accumulation (Virto et al. 2015). The soil structure (mainly calcic soils) in Marche region, Italy is quite similar to the soil in investigated area from Bulgaria (Yaneva et al. 2015). In Italy the mean annual hours of sunshine value ( $2516 \mathrm{~h})$ is the highest compared with the other investigated countries. However, the highest humidity is also recorded, due to high rainfall (more than $900 \mathrm{~mm}$ per year). It is supposed that because all these aspects the quantity of cyclitols detected in samples originated from Italy remains lower. In France, Germany, Poland and Switzerland, all with $\mathrm{Cfb}$ climate type, the mean annual hours of sunshine is lower (between $1569 \mathrm{~h}$ in Poland and $1794 \mathrm{~h}$ in France) compared with the previous mentioned countries. In the soil structure of these countries, there are some similarities. All these were reflected in close amounts of cyclitols detected in samples originated from these countries, which were lower than in those countries presented above.

Consequently, the cultivability place seems to play an important role onto the cyclitols amounts detected, especially through soil type. The fertile soils with strong human influence and with history of long and intensive agricultural use leading into the accumulation of soluble salts evidenced more cyclitols' accumulation in alfalfa plant. All the mentioned above proved the potential of alfalfa to become an industrial crop used for cyclitols extraction. This is easy to be achieved if alfalfa plant is growing in drought conditions, on saline soils, and less atmospherically humidity.

\section{The wished impacts of our study to environment}

In order to highlight a take home message broken down from our study, we will encourage alfalfa cultivation as a sustainable agricultural production. Not just because of the cyclitols importance presented in our study, but also for the other multiple benefits attracted by cultivation of this forage crop on environment. Alfalfa presents good adaptation (by growing on many different soil types), great versatility (it can survive under a wide range of climatic conditions), and is widespread use by occupying significant amount of farmlands, fact that makes it extremely important for the environment.

Nitrogen-fixing ability of alfalfa in association with Rhizobium bacteria is probably the biggest benefit to the environment offered by this plant. This is because in case of biologically fixed nitrogen, the risk of nitrogen containing runoff and likelihood of leaching is eliminated (Jogezai et al. 2019).

Alfalfa is also very important for crop rotations, because it has the ability to improve soil tilth resulting in a better water infiltration, due to the root channels that afford deeper rooting, and support the growing of other plants that follows alfalfa (Jogezai et al. 2019).

Wildlife enhancement is greatly support by alfalfa. Wild animals consume alfalfa forage, and/or use it as a place of refuge or for nesting. In addition, there is a high underground activity in an alfalfa field that includes by mice, voles, ground squirrels, etc. Moreover, alfalfa is a great insectary as well. Planting alfalfa crops in some certain area may keep wild animals in areas where they are desired. Esthetic value of "out in the country" by breathing the fresh air and enjoying the scenery is increased by bloomed fields with alfalfa that provide a pleasant sight.

Moreover, economically speaking, alfalfa contributes to society development in countless ways. It is an important crop for animals that produce meat, milk, eggs, etc., feed for zoo animals and for dairy cattle, horses, sheep, as well as for 
other forage-consuming creatures. It can bloom several times a year, and that makes it also an important source of nectar for honey production. Due to the bioactive components contained in alfalfa, this forage crop can become an important and cheap source for their extraction and further utilization in food, pharmaceutical or cosmetology industry.

\section{Conclusion}

As a conclusion regarding elicitors' influence on cyclitols production, we can state that $\mathrm{NaCl}$, which triggers both an osmotic and an ionic stress in plants, has increased significantly the quantities of all three detected cyclitols in alfalfa seedlings. $\mathrm{Zn}\left(\mathrm{NO}_{3}\right)_{2}$ proved to increase the amount of myoinositol, while $D$-pinitol and $D$-chiro-inositol amount was lower, compared with controls. No increase was detected in samples elicited with $\mathrm{AgNO}_{3}$; moreover, the quantities of cyclitols were lower than in control samples.

Concerning the seasonal impact, almost a double amount of cyclitols was detected in samples harvested in August compared with those cut down in May for both investigated countries. We have to mention therefore that the highest quantity of cyclitols was detected in samples from Romania, as compared with Poland. The total amount of cyclitols was strongly positively correlated $(r=0.957, p=0.01)$ with the number of sunny days and strongly negatively correlated ( $r=-0.989, p=0.01$ ) with humidity. The seasonal influence was highlighted especially for D-pinitol, the major cyclitol constitutive of alfalfa.

Cultivability place proved to play an important role onto the cyclitols amounts found, especially through soil type. The fertile soils with strong human influence and with history of long and intensive agricultural use, leading into the accumulation of soluble salts, evidenced more cyclitols' accumulation in alfalfa plant. More specifically, the highest quantities of cyclitols were detected in samples originated from Serbia, followed by Romania and Ukraine.

All the factors mentioned above proved the potential of alfalfa to become an industrial crop used for cyclitols extraction. This is easy to be achieved if alfalfa plant is growing in drought conditions, with saline soils, and less atmospherically humidity. Moreover, soil salinity can be adjusted using elicitors which act as ionic or osmotic stressing agents.

Acknowledgements This article is in memoriam Adrian Berinde, which helped in samples collection and who is not with us anymore today. Special thanks to Katarzyna Rafińska and Mădălina Popa from Nicolaus Copernicus University for the help provided in seedlings growing. The authors are grateful to Goran Anačkov, Department of Biology and Ecology, Faculty of Sciences, University of Novi Sad, for determination of plant material. We are grateful to all of our colleagues \& friends who helped us with the vegetal samples collection from different countries: Myroslaw Sprynskyy (Ukraine), Aleksandra Cvetanovic (Serbia), Adrian Berinde and Didier Rolette (Switzerland),
Iuliana Muresan (Italy), Pavel Georgiev (Bulgaria), Ioana Bucila and Gheorghe Ratiu (Romania), Doru Bugheanu (France), and Iuliana Teodora Bolboaca (Germany).

Funding This work was financed from the grant BIOSTRATEG2/298205/9/NCBR/2016 attributed by the National Center for Research and Development (Warsaw, Poland).

\section{Compliance with ethical standards}

Conflict of interest The authors declare no conflict of interest.

Open Access This article is licensed under a Creative Commons Attribution 4.0 International License, which permits use, sharing, adaptation, distribution and reproduction in any medium or format, as long as you give appropriate credit to the original author(s) and the source, provide a link to the Creative Commons licence, and indicate if changes were made. The images or other third party material in this article are included in the article's Creative Commons licence, unless indicated otherwise in a credit line to the material. If material is not included in the article's Creative Commons licence and your intended use is not permitted by statutory regulation or exceeds the permitted use, you will need to obtain permission directly from the copyright holder. To view a copy of this licence, visit http://creativecommons.org/licenses/by/4.0/.

\section{Reference}

Al-Suod H, Gadzała-Kopciuch R, Buszewski B (2018a) Simultaneous HPLC-ELSD determination of sugars and cyclitols in different parts of Phacelia tanacetifolia, Benth. Biochem Syst Ecol 80:32-38. https://doi.org/10.1016/j.bse.2018.06.003

Al-Suod H, Ligor M, Ratiu IA, Rafinska K, Górecki R, Buszewski B (2017) A window on cyclitols: characterization and analytics of inositols. Phytochem Lett 20:507-519. https://doi.org/10.1016/j. phytol.2016.12.009

Al-Suod H, Ratiu IA, Krakowska-Sieprawska A, Lahuta L, Górecki R, Buszewski B (2019a) Supercritical fluid extraction in isolation of cyclitols and sugars from chamomile flowers. J Sep Sci 42:3243-3252. https://doi.org/10.1002/jssc.201900539

Al-Suod H, Ratiu IA, Ligor M, Ligor T, Buszewski B (2018b) Determination of sugars and cyclitols isolated from various morphological parts of Medicago sativa L. J Sep Sci 41:1118-1128. https://doi. org/10.1002/jssc. 201701147

Al-Suod H, Ratiu IA, Górecki R, Buszewski B (2019b) Pressurized liquid extraction of cyclitols and sugars: optimization of extraction parameters and selective separation. J Sep Sci. https://doi. org/10.1002/jssc. 201801269

Bennett RN, Wallsgrove RM (1994) Secondary metabolites in plant defence mechanisms. New Phytol 127:617-633. https://doi. org/10.1111/j.1469-8137.1994.tb02968.x

Bongue-Bartelsman M, Phillips DA (1995) Nitrogen stress regulates gene expression of enzymes in the flavonoid biosynthetic pathway of tomato. Plant Physiol Biochem 33:539-546

Cheang KI, Baillargeon JP, Essah PA, Ostlund RE Jr, Apridonize T, Islam L, Nestler JE (2008) Insulin-stimulated release of D-chiroinositol-containing inositolphosphoglycan mediator correlates with insulin sensitivity in women with polycystic ovary syndrome. Metab, Clin Exp 57:1390-1397. https://doi.org/10.1016/j.metab ol.2008.05.008 
Coli M, Guerri L, Rubellini P (2015) Geotechnical characterization of the Florence (Italy) soils. Jpn Geotech Soc Special Publication. https://doi.org/10.3208/jgssp.TC301-02

Costantini EAC, Urbano F, L'Abate G (2004) Soil regions of Italy. http://www.soilmaps.it/download/csi-BrochureSR_a4.pdf, Accessed in 23.08.2018.

Costantino D, Minozzi G, Minozzi F, Guaraldi C (2009) Metabolic and hormonal effects of myo-inositol in women with polycystic ovary syndrome: a double-blind trial. Rev Med Pharmacol Sci 13:105-110

Dixon RA, Paiva N (1995) Stressed induced phenyl propanoid metabolism. Plant Cell 7:1085-1097. https://doi.org/10.1105/ tpc.7.7.1085

Fougere F, Le Rudulier D, Streeter JG (1991) Effects of salt stress on amino acid, organic acid, and carbohydrate composition of roots, bacteroids, and cytosol of Alfalfa (Medicago sativa L.). Plant Physiol 96:1228-1236. https://doi.org/10.1104/pp.96.4.1228

Hernandez-Mijares A, Banuls C, Peris JE, Monzo N, Jover A, Bellod L, Victor VM, Rocha M (2013) A single acute dose of pinitol from a naturally-occurring food ingredient decreases hyperglycaemia and circulating insulin levels in healthy subjects. Food Chem 141:1267-1272. https://doi.org/10.1016/j.foodchem.2013.04.042

Hossain MS, Persicke M, El-Sayed AI, Kalinowski J, Dietz KJ (2017) Metabolite profiling at the cellular and subcellular level reveals metabolites associated with salinity tolerance in sugar beet. J Exp Bot 68:5961-5976. https://doi.org/10.1093/jxb/erx388

http://enciclopediaromaniei.ro/wiki/Jude\%C5\%A3ul_Hunedoara, accessed in 23.08.2018.

https://en.wikipedia.org/wiki/Mutterstadt, accessed in 22.08.2018

https://repozytorium.umk.pl/bitstream/handle/item/4459/5.-Urban -Soils-Surveys-5.3-The-case-of-Toru\%C5\%84-_P.-Charzynski -_-P.-Hulisz_-full-text_compr.pdf?sequence $=1$, accessed in 23.08.2018.

https://www.climatedata.eu/climate.php?loc $=$ frxx $0074 \& l a n g=e n$, accessed in 22.08.2018

https://www.climatedata.eu/climate.php?loc $=$ srxx0005\&lang $=e n$, accessed in 22.08.2018.

https://www.climatedata.eu/country.php?cc=it\&lang=en, accessed in 22.08 .2018

https://www.climatedata.eu/country.php?cc=pl\&lang=en, accessed in 22.08.2018

https://www.climatedata.eu/country.php?cc=ro\&lang=en, accessed in 22.08.2018

https://www.climatedata.eu/country.php?cc $=$ sz\&lang=en, accessed in 22.08.2018

https://www.weatheronline.co.uk/reports/climate/Ukraine.htm, accessed in 22.08.2018

Kido EA, Ferreira Neto HRC, Silva RLO, Belarmino LC, Bezerra Neto JP, Soares-Cavalcanti NM, Pandolfi V, Da Silva M, Nepomuceno AL, Benko-Iseppon AM (2013) Expression dynamics and genome distribution of osmoprotectants in soybean: identifying important components to face abiotic stress. BMC Bioinform 14:S7. https:// doi.org/10.1186/1471-2105-14-S1-S7

Kulbat K (2016) The role of phenolic compounds in plant resistance. Biotechnol Food Sci 80:97-108

Larson RA (1988) The antioxidants of higher plants. Phytochem 27:969-978. https://doi.org/10.1016/0031-9422(88)80254-1

Lavola A, Aphalo PJ, Lahti M, Julkunen-Tiitto R (2003) Nutrient availability and the effect of increasing UV-B radiation on secondary plant compounds in Scots pine. Environ Exp Bot 49:49-60. https ://doi.org/10.1016/S0098-8472(02)00057-6
Li TSC, Mazza G, Cottrell AC, Gao L (1996) Ginsenosides in roots and leaves of American ginseng. J Agric Food Chem 44:717-720. https://doi.org/10.1021/jf950309f

Liang B, Huang X, Zhang G, Zhang F, Zhou Q (2006) Effect of lanthanum on plants under supplementary ultraviolet $\mathrm{B}$ radiation: Effect of lanthanum on flavonoid contents in Soybean seedlings exposed to supplementary ultraviolet-B radiation. J Rare Earths 24:613-616. https://doi.org/10.1016/S1002-0721(06)60174-9

Licina V, Nesic L, Belic M, Hadzic V, Sekulic P, Vasin J, Ninkov J (2011) The Soils of Serbia and Their Degradation. Field Veg Crop Res 48:285-290. https://doi.org/10.5937/ratpov11022851

Ligor M, Ratiu IA, Kiełbasa A, Al-Suod H, Buszewski B (2018) Extraction approaches used for the determination of biologically active compounds (cyclitols, polyphenols and saponins) isolated from plant material. Electrophoresis 39:1860-1874. https://doi. org/10.1002/elps.201700431

Loewus FA, Murthy PPN (2000) Myo-Inositol metabolism in plants. Plant Sci 150:1-19. https://doi.org/10.1016/S0168-9452(99)00150 $-8$

Medvedev VV, Laktionova TN (2012) Degradation rehabilitation and conservation of soils. analysis of the experience of European countries in soil monitoring. Eurasian Soil Sci. 45:90-97

Morison JIL, Lawlor DW (1999) Interactions between increasing $\mathrm{CO}_{2}$ concentration and temperature on plant growth. Plant, Cell Environ 22:659-682. https://doi.org/10.1046/j.1365-3040.1999.00443 . $\mathrm{x}$

Nadeau P, Delaney S, Chouinard L (1987) Effects of cold hardening on the regulation of polyamine levels in wheat (Triticum aestivum L.) and Alfalfa (Medicago sativa L.). Plant Physiol 8:73-77

Ncube B, Finnie JF, Van Staden J (2012) Quality from the field: The impact of environmental factors as quality determinants in medicinal plants. S Afr J Bot 82:11-20. https://doi.org/10.1016/j. sajb.2012.05.009

Orthen B, Popp M (2000) Cyclitols as cryoprotectants for spinach and chickpea thylakoids. Environ Exp Bot 44:125-132. https://doi. org/10.1016/s0098-8472(00)00061-7

Pasquier C, Bourennane H, Cousin I, Séger M, Dabas M, Thiesson J, Tabbagh T (2016) Comparison between thermal airborne remote sensing, multi-depth electrical resistivity profiling, and soil mapping: an example from Beauce (Loiret, France). Near Surface Geophy 14:345-356. https://doi.org/10.3997/1873-0604.2016021

Petrusa LM, Winicov I (1997) Proline status in salt tolerant and salt sensitive alfalfa cell lines and plants in response to $\mathrm{NaCl}$. Plant Physiol Biochem 35:303-310

Pitta-Alvarez SI, Spollansky TC, Giullietti AM (2000) The influence of different biotic and abiotic elicitors on the production and profile of tropane alkaloids in hairy root cultures of Brugmansia candida. Enzyme Microb Technol 26:252-258. https://doi.org/10.1016/ S0141-0229(99)00137-4

Ramakrishna A, Ravishankar GA (2011) Influence of abiotic stress signals on secondary metabolites in plants. Plant Signal Behav 6:1720-1731. https://doi.org/10.4161/psb.6.11.17613

Ratiu IA, Al-Suod H, Ligor M, Ligor T, Railean-Plugaru V, Buszewski B (2018) Complex investigation of extraction techniques applied for cyclitols and sugars isolation from different species of Solidago genus. Electrophoresis 39:1966-1974. https://doi. org/10.1002/elps.201700419

Ratiu IA, Al-Suod H, Ligor M, Ligor T, Krakowska A, Górecki R, Buszewski B (2019) Simultaneous determination of cyclitols and sugars following a comprehensive investigation of 40 plants. Food Anal Meth. https://doi.org/10.1007/s12161-019-01481-z 
Ratiu IA, Al-Suod H, Bukowska M, Ligor M, Buszewski B (2020) Correlation study of honey regarding their physicochemical properties and sugars and cyclitols content. Molecules 25:34. https://doi. org/10.3390/molecules25010034

Rengarajan T, Nandakumar N, Rajendran P, Ganesh MK, Balasubramanian MP, Nishigaki I (2015) D-pinitol mitigates tumor growth by modulating interleukins and hormones and induces apoptosis in rat breast carcinogenesis through inhibition of NF-Kb. J Physiol Biochem 71:191-204. https://doi.org/10.1007/s13105-015-0397-9

Jogezai S, Taj MK, Shahzad F, Khan AW, Taj I, Yasmeen S, Ullah N, Azam S, Lalbibi Sazain B, Ali SA, Hussain A, Samreen Z (2019) Role of alfalfa in natural environment. J Biodiv Env Sci 15:25-31

Sengupta S, Majumder AL (2010) Porteresia coarctata (Roxb.) tateoka, a wild rice: a potential model for studying salt-stress biology in rice. Plant, Cell Environ 33:526-542. https://doi.org/10.111 1/j.1365-3040.2009.02054.x

Sengupta S, Patra B, Ray S, Majumder AL (2008) Inositol methyl tranferase from a halophytic wild rice, Porteresia coarctata Roxb. (Tateoka): regulation of pinitol synthesis under abiotic stress. Plant, Cell Environ 31:1442-1459. https://doi.org/10.111 1/j.1365-3040.2008.01850.x

Sikorski L, Piotrowicz-Cieslak AI, Adomas B (2013) Phytotoxicity of sodium cloride towards common duckweed (Lemna minor L.) and yellow lupin (Lupinus Luteus L.). Arch Environ Prot 39:117-128. https://doi.org/10.2478/aep-2013-0018

Szakiel A, Paczkowski C, Henry M (2011) Influence of environmental abiotic factors on the content of saponins in plants. Phytochem Rev 10:471-491. https://doi.org/10.1007/s11101-010-9177-x
Tóth G, Montanarella L, Stolbovoy V, Máté F, Bódis K, Jones A, Panagos P, Van Liedekerke M (2008) Soils of the European union. JRC Sci Tech Rep. https://doi.org/10.2788/87029

Tuteja N, Mahajan S (2007) Calcium signaling network in plants an overview. Plant Signal Behav 2:79-85. https://doi.org/10.4161/ psb.2.2.4176

Virto I, Imaz M, Fernández-Ugalde O, Gartzia-Bengoetxea N, Enrique A, Bescansa P (2015) Soil degradation \& soil quality in western Europe: current situation and future perspectives. Sustainability 7:313-365. https://doi.org/10.3390/su7010313

Winkel-Shirley B (2001) Flavonoid biosynthesis, a colorful model for genetics, biochemistry, cell biology and biotechnology. Plant Physiol 26:485-493. https://doi.org/10.1104/pp.126.2.485

Yaneva M, Stanimirova T, Kenderova R (2015) Comparative mineralogical characteristics of red soils from South Bulgaria. Eurasian J Soil Sci 4:100-106. https://doi.org/10.18393/ejss.70419

Zhang W, Seki M, Furusaki S (1997) Effect of temperature and its shift on growth and anthocyanin production in suspension cultures of strawberry cells. Plant Sci 127:207-214. https://doi.org/10.1016/ S0168-9452(97)00124-6

Zheng K, Zha Z, Lin N, Wu Y, Xu Y, Zhang W (2017) Protective effect of pinitol against inflammatory mediators of rheumatoid arthritis via inhibition of protein tyrosine phosphatase non-receptor type 22 (PTPN22). Med Sci Monit 23:1923-1932. https://doi. org/10.12659/msm.903357 